\title{
A (In)Dignidade nos Direitos à Vida e à Morte em Caso de Doenças Terminais ou Pacientes em Coma a partir do Filme "Bella Addormentata"
}

\author{
Rafael Marcílio Xerez \\ Doutor em Direito pela Universidade Federal da Bahia. Professor dos cursos de \\ pós-graduação (Mestrado e Doutorado) da Universidade de Fortaleza. E-mail: \\ rafaelmx@unifor.br
}

\section{Humberto Cardoso Pinto}

Mestrando em Direito Constitucional pela Universidade de Fortaleza. E-mail: humbertocpinto@gmail.com

\begin{abstract}
Resumo: O direito à morte digna gera opiniões opostas no âmbito jurídico, em especial quanto à possibilidade de decisão pela descontinuidade da vida por doentes terminais ou pacientes em coma. A discussão ocorre em torno da Dignidade da Pessoa Humana e da Autonomia de Vontade, já que, nos casos de doenças incuráveis e terminais, a manutenção da vida por meio de medicamentos e equipamentos costuma gerar dor e sofrimento aos pacientes. As questões envolvendo métodos como Eutanásia, Ortotanásia e Suicídio Assistido, além da Diretiva Antecipada da Vontade, como possibilidades para os pacientes, dividem opiniões. O filme "Bella Addormentata" trata destas questões, em especial no caso de Eluana Englaro, em coma há dezessete anos, que provocou indagação sobre a compulsoriedade ou não na manutenção da vida dos pacientes em coma. A pesquisa é bibliográfica e documental. Tem por objetivo analisar se deve ser garantido ao paciente em estado terminal ou em coma o direito à escolha pela morte em detrimento do prolongamento de sua vida por meios artificiais. Como direito fundamental, o direito à morte digna deve ser assegurado aos pacientes em coma ou terminais, desde que com prévia manifestação de sua vontade de não submissão a tratamentos prolongadores da vida.
\end{abstract}

Palavras-chave: Direito à morte digna. Eutanásia. Suicídio Assistido. Ortotanásia. Diretiva Antecipada de Vontade.

\section{UNIVERSIDADE FEDERAL DA PARAÍBA}




\title{
A (In)Dignidade nos Direitos à Vida e à Morte em Caso de Doenças Terminais ou Pacientes em Coma a partir do Filme "Bella Addormentata"
}

\author{
Rafael Marcílio Xerez ${ }^{1}$ \\ Humberto Cardoso Pinto
}

1 INTRODUÇÃO

$\mathrm{O}$ direito à vida é direito fundamental consubstanciado no caput do artigo $5^{\circ}$ da Constituição Federal de 1988 (CF), enquanto a Dignidade da Pessoa Humana é Princípio e fundamento do Estado Democrático de Direito brasileiro, conforme exposto no artigo $1^{\circ}, \mathrm{I}$, do mesmo diploma (BRASIL, 1988). Fala-se em direito à vida digna, já que o direito à vida não se limita ao direito de sobreviver, mas refere-se ao direito a viver com dignidade. Do direito à vida digna, e do que se verifica na cláusula de abertura prevista no parágrafo $2^{\circ}$ do artigo $5^{\circ}$ da $\mathrm{CF}$, ao prever a possibilidade de existência de direitos e garantias fundamentais a partir dos Princípios adotados pela $\mathrm{CF}$ (BRASIL, 1988), há a possibilidade de se defender o direito à morte digna.

Diante de tal fato, e levando-se em consideração a Autonomia da Vontade e a própria Dignidade da Pessoa Humana, deve-se questionar se, em casos de pacientes acometidos por doenças

\footnotetext{
${ }^{1}$ Juiz titular da $2^{\mathrm{a}}$ Vara do Trabalho de Fortaleza-CE.
} 
A (In)Dignidade nos Direitos à Vida e à Morte em Caso de...

terminais ou em coma, a manutenção de suas vidas sob qualquer hipótese é de observância obrigatória pelos profissionais da saúde, ou há possibilidade de assegurar-se, ao paciente, ou a quem o represente, a escolha pela manutenção da vida ou pela morte digna. Assim, é que se verifica a possibilidade da utilização, pelo paciente em estado terminal, das Diretivas Antecipadas de Vontade, pelas quais o paciente ou seu representante expõe a quais tratamentos deseja submeter-se. No caso de decisão tomada diretamente pelo paciente, requer-se, obviamente, que haja sido realizada com antecedência ao estado de inconsciência que lhe sobrevenha.

O filme "Bella Addormentata” (“A Bela que Dorme”, em português) traz em seu conteúdo discussões acerca do direito à vida e à morte dignas. Neste tocante, aborda questões sobre possibilidade de escolha, pelo paciente ou por quem o represente, quanto à continuidade ou não da manutenção da vida do doente, no caso de coma, como ocorrido com Eluana Englaro, ou, ainda, no caso de doença terminal, como se passa com Emma, mulher do então senador italiano Uliano Beffardi. Mostram-se dois pontos de vista: o de obrigatória manutenção da vida, como valor absoluto, e o da possibilidade de escolha pela morte, para aliviar a dor e o sofrimento, com manutenção da Dignidade e da Autonomia. No caso de Eluana Englaro, a liberdade de escolha seria exercida pela família, enquanto na situação de Emma, a escolha caberia a ela.

A problemática a ser tratada é: deve-se assegurar, ao paciente em estado terminal ou em coma, a possibilidade de escolher pela morte, em detrimento do prolongamento de sua vida por meios artificiais? O objetivo geral é analisar se deve ser garantido ao paciente em estado terminal ou em coma o direito à escolha pela morte, em detrimento do prolongamento de sua vida por meios artificiais. Os objetivos específicos são: analisar se há, no Direito brasileiro, possibilidade de ser atribuída ao paciente em estado terminal a escolha entre o prolongamento da vida e a morte, como salvaguarda da Autonomia da Vontade e da Dignidade da Pessoa 
Humana; analisar se há, no Direito nacional, possibilidade de salvaguardar, a representante do paciente em coma, a escolha por sua morte, ao invés do prolongamento de sua vida por meios artificiais; analisar se as Diretivas Antecipadas de Vontade são instrumentos válidos enquanto asseguradores ao paciente em estado terminal ou em coma, ou quem o represente, de fazer sua escolha pela vida ou pela morte.

A pesquisa é, quanto à fonte, bibliográfica e documental, pois desenvolve-se pelo exposto em artigos e livros e utiliza, como outras fontes, a legislação e o filme, ainda não submetido a tratamento analítico (GIL, 2002, p. 44-45).

$\mathrm{O}$ artigo estrutura-se da seguinte forma: primeiramente, fazze exposição do filme "Bella Addormentata", pela narrativa dos fatos mais relevantes; passa-se, então, pela inclusão do Direito na Arte, expondo-se em que ponto a Arte pode contribuir para análise de questão jurídica; depois, pela disposição dos direitos à vida e à morte dignas e pela previsão das Diretivas Antecipadas de Vontade em resolução do Conselho Federal de Medicina (CFM) e a reflexão sobre sua validade, e prossegue-se pela exposição sobre os métodos de Eutanásia, Ortotanásia e Suicídio Assistido, tomando-se como meio as reflexões sobre a vida e a morte retratadas no filme.

\section{O FILME "BELLA ADDORMENTATA" E A REFLEXÃO SOBRE OS DIREITOS À VIDA E À MORTE}

O filme é utilizado para provocar a discussão sobre possível escolha entre os direitos à vida digna e à morte digna, quando em casos específicos de pacientes em coma e doentes terminais. Dessa forma, parte-se da obra artística para a discussão jurídica. Assim, faz- 
A (In)Dignidade nos Direitos à Vida e à Morte em Caso de...

se descrição breve do filme para, então, mostrar-se a relação possível entre Direito e Arte, sendo a Arte meio de reprodução de questionamentos jurídicos.

\subsection{EXPOSIÇÃO DO FILME “BELLA ADDORMENTATA"}

O filme "Bella Addormentata" é um filme de drama do diretor italiano Marco Bellocchio, a tratar da história real, ocorrida na Itália ao longo do ano 2009, de Eluana Englaro, uma jovem que se encontra em coma há dezessete anos. Este filme traz, em seu contexto, discussões relacionadas à manutenção do direito à vida, como valor absoluto, em casos de pacientes em coma, como ocorrido na história principal, de Eluana Englaro, ou, ainda, em casos de pacientes terminais, como ocorre com Emma, diante do questionamento se pode ser garantido o direito a não mais manter alguém vivo por meios artificiais.

O caso real de Eluana provoca discussões entre os favoráveis e os contrários à possibilidade de desligamento dos aparelhos que a mantêm viva, e mobiliza o parlamento italiano no tocante à aprovação ou não da Lei ${ }^{0}$ 1.369, na época em que Silvio Berlusconi era o Presidente do Conselho de Ministros (Primeiro-Ministro). A aprovação deste diploma legal abordaria questões referentes a impossibilidade de liberdade de escolha quanto a aspectos como a alimentação intravenosa e a transferência de sangue, enfim, mostrarse-ia contrária à morte assistida.

As manifestações contrárias e favoráveis à lei perpassam toda a obra: em lados opostos estão os favoráveis à possibilidade de escolha e os favoráveis à manutenção da vida de forma compulsória. Neste último grupo, encontram-se católicos, incluindo-se a filha do senador Uliano Beffardi, Maria.

O partido político do senador Beffardi decide votar a favor da lei, enquanto Beffardi é contrário à lei, sendo a favor da liberdade de 
escolha. O próprio senador, conforme se observa ao longo do filme, passou por situação dramática, já que sua esposa, Emma, a qual se encontrava acometida de doença em estado crítico, terminal, rogou a seu marido para ajudá-la a pôr fim à sua vida. O senador, angustiado, desligou os aparelhos que a mantinham viva, fato presenciado discretamente por Maria.

Há, ademais, situações ficcionais a ocorrerem em paralelo à história de Eluana. Há o caso de uma família, tendo como mãe uma atriz famosa, como pai, um ator, e dois filhos, Federico e Rosa. Rosa encontra-se em coma, sobrevivendo por meio de aparelho de respiração artificial, enquanto a mãe se põe ao seu lado durante todo o tempo, rezando, sozinha ou com as enfermeiras religiosas, resumindo sua vida a observar sua filha em coma, esperançosa pela recuperação. Para tanto, importa-se cada vez menos com sua vida cotidiana: abandona sua carreira de atriz e não valoriza mais seu marido e seu filho. Federico, por outro lado, tem o objetivo de tornarse ator, e, desejoso de ingressar na Academia, para formar-se em Artes Cênicas, busca ajuda da mãe em seu preparo para o exame de ingresso, ao que ela refuta constantemente.

Federico, percebendo a situação da mãe, mostra-se contrariado e busca libertá-la da condição em que vivia, e, assim, desconecta o respirador artificial de sua irmã, ao que seu pai, ao perceber algo errado, corre ao quarto da filha. Federico, diante da súplica de seu pai, o qual lhe afirma a necessidade de que respeite a vontade de sua mãe, reconecta o equipamento. $\mathrm{O}$ contexto deixa claro que a família vive momentos conflituosos e turbulentos em face da condição de Rosa.

O filme, enfim, é relevante no tratamento do tema do artigo, quanto à questão de, em caso de pacientes terminais ou em coma, haver ou não a possibilidade de escolha pela interrupção da vida. A análise jurídica é pautada em face da legislação brasileira, sendo o filme italiano base para essa discussão. Abre-se, ademais, a 
A (In)Dignidade nos Direitos à Vida e à Morte em Caso de...

possibilidade de se questionar se, em sendo possível o respeito à decisão do paciente que se encontre em uma das situações mencionadas, as Diretivas Antecipadas de Vontade seriam o meio adequado para esse fim.

2.2 O DIREITO NA ARTE OU A ARTE COMO INSTRUMENTO DE REFLEXÃO E COMPREENSÃO DO DIREITO

É inegável que a Arte pode funcionar como meio de exposição de críticas e de discussões de temas sociais e culturais sensíveis ao Direito. Por isso, recorreu-se ao filme em comento para fundamentar a análise sobre direitos à vida e à morte, levando-se em consideração o ordenamento jurídico brasileiro e a discussão acerca de Autonomia da Vontade e Dignidade da Pessoa Humana.

Uma das modalidades possíveis de relação entre Direito e Arte é o Direito na Arte, na qual se verifica, como tema da obra de Arte, o Direito. Assim, a obra em que figura esta modalidade de relação entre Direito e Arte tem, em seu tema, associação com o Direito. A relação que se faz entre o filme "Bella Addormentata" e o tema jurídico em liça dá-se por "representação de situações da vida humana que inspiram uma reflexão sobre direitos subjetivos" (XEREZ, 2014, p. 234). Afinal, a obra representa questões a envolverem vida, dignidade, liberdade, que bem caracterizam a modalidade de Direito na Arte, com representações de situações a provocarem indagações e reflexões sobre os direitos subjetivos de doentes terminais ou em coma à vida e à morte.

Portanto, a utilização do filme ocorre com objetivo de reflexão e estudo acerca do direito fundamental à vida e à possibilidade de dela dispor pelo exercício de um implícito direito fundamental à morte, quando em face de casos de acometimento de doenças 
terminais e em situações de coma. Assim, é possível trazer à baila circunstâncias atuantes sobre a temática, como o são, por exemplo, o fundamento da Dignidade da Pessoa Humana, a Autonomia de Vontade e os limites impostos por lei, sem esquecer os aspectos humanos incidentes sobre a questão.

\section{DIREITO À VIDA DIGNA E DIREITO À MORTE DIGNA}

Inicialmente, é necessário que se delineie o que é Dignidade da Pessoa Humana, a qual se põe como Princípio e fundamento do Estado Democrático de Direito brasileiro, conforme exposto no artigo $1^{\mathrm{o}}$, caput, e inciso III da CF (BRASIL, 1988). Isto significa que, por ser fundamento, é-lhe dado caráter de supremacia. Portanto, na busca da salvaguarda de direitos essenciais e de objetivos a serem perquiridos pelo País e por seu ordenamento, a Dignidade da Pessoa Humana deve ser observada.

Antes de incidir sobre a definição de Dignidade da Pessoa Humana, é mister salientar que o Princípio da Dignidade da Pessoa Humana está localizado no início do texto da CF, no título destinado aos Princípios fundamentais, encontrando-se logo após o preâmbulo e antes das disposições referentes aos direitos fundamentais. O Constituinte, dessa forma, demonstrou seu intuito de conceder aos Princípios fundamentais a característica de normas que embasam a integralidade da ordem constitucional, sobretudo as normas concernentes aos direitos e garantias fundamentais. Nesse contexto, junto com as normas de direitos e garantias fundamentais, os Princípios fundamentais, como o da Dignidade da Pessoa Humana, constituem o núcleo essencial da $\mathrm{CF}$. Além de ser fundamento 


\section{A (In)Dignidade nos Direitos à Vida e à Morte em Caso de...}

inerente aos direitos fundamentais, o Princípio em comento origina direitos fundamentais autônomos (SARLET, 2009, p. 69-77).

Passando a uma busca pela definição do que constitui a referida Dignidade da Pessoa Humana, pode-se dispor que a dignidade é receber respeito pelos outros, manter liberdade e ser igual aos demais, com salvaguarda de seus direitos e obrigações pelo ordenamento jurídico. Tal Princípio é relevante e apresenta "sentido subjetivo, pois depende de cada indivíduo, do seu respeito às diferenças físicas, sociais e culturais, de seus sentimentos e da sua consciência" (CARVALHO, 2012, p. 18).

Pelo exposto retro, percebe-se que a um só tempo a dignidade é concernente à liberdade individual, à igualdade entre as pessoas e à proteção a direitos e obrigações, entre os quais certamente estão os direitos fundamentais, constituindo-se em requisito necessário na exegese de normas referentes aos direitos e garantias fundamentais, uma vez que os embasa. O Princípio da Dignidade da Pessoa Humana, para ser observado, deve levar em conta o sentido subjetivo e as diferenças apresentadas pelos indivíduos em muitas dimensões, entre as quais, sua consciência.

Os direitos fundamentais em geral, por sua vez, caracterizamse, entre outras coisas, por terem função dignificadora, já que têm por escopo a salvaguarda da Dignidade da Pessoa Humana e, portanto, são defensores da esfera humana individual em face de interferências indevidas do Poder Público e de particulares. Ainda, como normas de otimização, detêm natureza principiológica e, assim, demandam, no caso concreto, a solução que melhor atenda ao direito (LOPES, 2001, p. 37).

Caracterizados os direitos fundamentais, inegável é a relação necessária e reflexiva entre a observância e a promoção deles, os quais devem ser efetivos e efetivados, e o Princípio da Dignidade da Pessoa Humana. Este Princípio, central no ordenamento constitucional brasileiro, incide sobre toda a ordem constitucional, 
mas, sobretudo, sobre os direitos fundamentais. Em sentido de reciprocidade, a Dignidade da Pessoa Humana só é observada quando concretizados os direitos e as garantias fundamentais.

Após análise sobre o Princípio da Dignidade da Pessoa Humana e sobre a caracterização dos direitos fundamentais em geral, mister é dispor sobre o direito à vida. Este direito funciona como pressuposto de todos os outros direitos constitucionais, pois encontram seus limites máximos de extensão na vida, e é infrutífero que se salvaguarde qualquer outro direito sem permitir que dele se usufrua e, para tanto, faz-se necessário que se esteja vivo. Assim, em princípio, no Brasil, o direito à vida é a principal objeção à existência de um direito de morrer (KRAVETZ; CASTRO, 2015, p. 356). Para o exercício pessoal de direitos, seguindo essa linha, certamente faz-se necessário que se esteja vivo, afinal o artigo $2^{\circ}$ do Código Civil de 2002 dispõe que "a personalidade civil da pessoa começa do nascimento com vida; mas a lei põe a salvo, desde a concepção, os direitos do nascituro" (BRASIL, 2002).

Ressalte-se, mais uma vez, que o Princípio da Dignidade da Pessoa Humana é fundamento do Estado Democrático de Direito brasileiro e, portanto, exerce papel primordial no ordenamento jurídico, além de ser de observância obrigatória e plena. Isso posto, em consonância com o visto anteriormente, o direito à vida constituise em direito à vida digna. Portanto, o questionamento sobre a necessidade de manter-se vivo o paciente em coma ou em estado terminal ganha relevância, a despeito de o direto à vida ser requisito necessário para a concretização dos demais direitos.

Delineado que o direito à vida se refere a uma vida com dignidade, ressalte-se que a dignidade em questão há de ser percebida a partir de uma visão pessoal, individualizada, especialmente do paciente em estado terminal, devendo, quando em enfrentamento de uma situação de morte inevitável e iminente, prevalecer sua Autonomia (FREITAS; ZILIO, 2016, p. 200). 
A (In)Dignidade nos Direitos à Vida e à Morte em Caso de...

Por sua vez, a consagração do Princípio da Autonomia, no âmbito da Bioética, demanda o consentimento livre e esclarecido do paciente, o qual passa a ser sujeito ativo na tomada de decisões sobre sua vida e sua saúde, especialmente sobre a quais tratamentos se submeterá ou não. Com efeito, ao profissional da saúde cabe o papel de prestar os esclarecimentos ao paciente (FREITAS; ZILIO, 2016, p. 200).

Não se pode olvidar que o elenco dos direitos e garantias fundamentais no caput e nos incisos do artigo $5^{\circ}$ da $\mathrm{CF}$, entre os quais o direito à vida, não esgota todos os direitos e garantias desta natureza. Afinal, conforme o parágrafo $2^{\circ}$ do mesmo artigo, o elenco expresso dos direitos e garantias na CF não é excludente de "outros decorrentes do regime e dos Princípios por ela adotados" (BRASIL, 1988). Há, pois, a possibilidade de direitos implícitos, pois decorrentes diretamente de Princípios adotados na $\mathrm{CF}$, bem como outros que provenham do regime. Isto posto, decorrência natural do direito à vida digna é o direito à morte digna.

Sobre o direito à vida digna, este condiz com o tratamento de cada pessoa "como um fim em si mesma, não podendo ser tratado como objeto, tendo em vista a vida humana possuir um valor intrínseco objetivo”, significando que o indivíduo mantém ligação íntima com suas vontades e objetivos. Acresça-se que o direito à vida deve ser considerado influenciado pelos Princípios constitucionais, entre os quais: o já mencionado da Dignidade da Pessoa Humana; integridade física e psíquica, e proibição de tratamento desumano e degradante, portanto, constituindo-se em direito à vida digna (COSTA; DUARTE, 2016, p. 8).

Os mesmos autores acima elencados, ao exporem sobre a morte digna durante a fase de doença terminal, defendem que o indivíduo, o qual possui autonomia no exercício de suas atividades no transcorrer de sua vida, também a possui durante o momento em que 
a morte se aproxima, em face de doença que avança a seu estágio fatal e incurável (COSTA; DUARTE, 2016, p. 9).

Conclusão necessária, após a reflexão sobre a temática, é que a morte digna, especialmente nos casos de pacientes terminais, caracteriza-se por ser aquela que se pauta na conjunção de dois elementos: "Autonomia do paciente e os deveres de cuidado que devem ser prestados pelos profissionais da saúde" (RECKZIEGEL; STEINMETZ, 2016, p. 95). Nessas circunstâncias, a morte digna é aquela que permite, ao paciente terminal, uma morte tranquila e humanizada (FREITAS; ZILIO, 2016, p. 200).

Quanto às discussões apresentadas no filme, deve-se pontuar suas diferenças, no que toca à possibilidade de opção pela vida ou pela morte: na situação de coma, a qual pode ser por vezes revertida, apesar dos dezessete anos transcorridos do caso real da jovem Eluana Englaro; por outro lado, questão de pacientes terminais, como ocorre com Emma. Em comum aos casos, a decisão de submissão ou não a tratamentos e aparelhos prolongadores da vida.

3.1 AS DIRETIVAS ANTECIPADAS DE VONTADE E SUA VALIDADE DIANTE DO ORDENAMENTO JURÍDICO BRASILEIRO

Concernente à possibilidade, em face de doença terminal, de se decidir por não recorrer ao prolongamento artificial da vida, optando-se pela morte a decorrer naturalmente, há os instrumentos das Diretivas Antecipadas de Vontade, previstas na Resolução $\mathrm{n}^{\mathrm{o}}$ 1.995/2012 do Conselho Federal de Medicina (CFM). Aplicam-se quando quem se encontra acometido por doença terminal está "em pleno gozo de suas faculdades mentais quando opta por não mais prolongar a dor”. A decisão pela vida ou morte resulta de integração 
A (In)Dignidade nos Direitos à Vida e à Morte em Caso de...

de preceitos morais, religiosos e terapêuticos (MARQUES; ALMEIDA, 2014, p. 9).

Há duas espécies de Diretivas Antecipadas de Vontade, quais sejam, o Testamento Vital e o Mandato Duradouro. O primeiro designa a declaração prévia de vontade do paciente, em pleno gozo de suas faculdades mentais e de manifestação. Não se faz necessário que já esteja acometido de doença terminal quando da declaração, e no instrumento a pessoa expressará os tratamentos e não tratamentos aos quais deseja ou não se submeter, a produzir efeito quando não mais lograr, em face de doença terminal, manifestar este ato de vontade. A segunda espécie é o Mandato Duradouro, pelo qual o paciente, redigindo-o auxiliado por um médico de confiança, disporá sobre "a interrupção ou suspensão de tratamentos extraordinários que adiam" a morte, mediante decisão tomada pelo procurador nomeado pelo enfermo, não cabendo suspensão dos tratamentos paliativos, os quais garantem benefícios à sua qualidade de vida (MARQUES; ALMEIDA, 2014, p. 10).

Supostamente, por meio das Diretivas Antecipadas de Vontade, o médico exime-se de qualquer responsabilidade em face da decisão do paciente. Entretanto, perceba-se que os instrumentos relatados não autorizam dar cabo à vida do paciente, mas tão somente decidir-se, pelo próprio doente ou pelo procurador nomeado, a quais tratamentos se submeterá quando não mais gozar de livre manifestação de sua vontade.

Sobre o objeto ora tratado, a Lei portuguesa $\mathrm{n}^{\circ}$ 25/2012, que regula as Diretivas Antecipadas de Vontade, traz, em seu artigo $2^{\circ}, 1$, definição de Testamento Vital, prevendo-o como documento redigido e revogável unilateralmente, subscrito por quem detenha capacidade plena quando de sua confecção, em que expressa, antecipadamente, sua vontade livre, consciente e esclarecida, no que toca aos cuidados com saúde que deseja ou não receber, quando, por algum motivo, não 
seja mais capaz de expressar sua vontade pessoalmente e de forma autônoma (PORTUGAL, 2012).

De acordo com o artigo $2^{0}, 2$ do mesmo documento citado acima, o Testamento Vital pode abranger os direitos do paciente de: não se submeter "a tratamento de suporte artificial das funções vitais"; não se submeter a tratamento "fútil, inútil ou desproporcionado no seu quadro clínico e de acordo com as boas práticas profissionais"; receber cuidados paliativos para controle de seu sofrimento ocasionado por doença grave ou irreversível; não se submeter a tratamentos experimentais; e "autorizar ou recusar a participação em programas de investigação científica ou ensaios clínicos" (PORTUGAL, 2012).

Dada essa exposição dos dispositivos legais portugueses, percebe-se que o Testamento Vital respeita, em grande medida, a autodeterminação do paciente em estado terminal, baseando-se em declaração prévia de suas vontades, em consonância com os já expostos direitos à vida digna e à morte digna, os quais são indissociáveis da Dignidade pessoal e da Autonomia desse tipo de paciente.

No sentido do exposto, as Diretivas Antecipadas de Vontade, tais como previstas no ordenamento português, relacionam-se com o respeito pela Dignidade da Pessoa Humana e com a autodeterminação prospectiva de quem recorre a esses instrumentos. Pauta-se, por conseguinte, na concepção de que o direito à vida não é integrado por um dever de viver, pois inexiste obrigação de alguém proteger sua própria vida. Afinal, o direito à vida, nessa seara, apresenta-se como o direito de alguém resguardar sua vida em relação a outrem (DIAS, 2016, p. 233-234), que, logicamente, dela não pode dispor.

As Diretivas Antecipadas de Vontade, portanto, asseguram o exercício de manifestação de vontade do paciente e, assim, sua 
A (In)Dignidade nos Direitos à Vida e à Morte em Caso de...

Autonomia nas escolhas, pelo menos quando em face de estado terminal de doença, ou seja, irreversibilidade do quadro de saúde. Diverso é o caso de quando o paciente se encontra em coma, ainda que prolongado, como o de Eluana Englaro, e as questões que dele emergem, concernentes à Autonomia de Vontade manifestada previamente, mediante Diretiva Antecipada de Vontade, ou à possibilidade de escolha por seus familiares ou alguém designado. $\mathrm{O}$ ordenamento jurídico brasileiro não permite, a priori, que, em face de doença grave, e mesmo em coma, se opte pela provocação de morte do paciente, negando-lhe, prima facie, a assistência pelos instrumentos referidos.

Observe-se, ainda, a situação, igualmente retratada no filme, do senador Beffardi, cuja esposa, hospitalizada e acometida de doença terminal, lhe pede para ajudar na abreviação de sua vida, ao que ele, de forma relutante, assente, ao desligar os aparelhos. Ele simplesmente atendeu a um pedido da esposa, movido por amor e compaixão em face do sofrimento desta. Acaso a situação em comento seja enquadrada como homicídio, previsto, no Código Penal brasileiro, no artigo 121, deve ser-lhe aplicada causa de diminuição de pena expresso no parágrafo $1^{0}$, já que o suposto crime teria ocorrido provocado por agente "impelido por motivo de relevante valor social ou moral" (BRASIL, 1940).

Na situação acima mencionada, problema merece ser trazido à tona, qual seja, se ao paciente, em estado terminal, ainda que não expresse sua escolha em Diretivas Antecipadas de Vontade, deve-se ou não ser concedida a liberdade de optar por sua morte, mesmo que tenha de contar com auxílio de terceiros. A discussão deve ser em torno da questão da Autonomia da Vontade, da Dignidade da Pessoa Humana e da possibilidade, em referidas circunstâncias, de dispor ou não da vida, a qual é direito fundamental.

O mencionado Princípio da Autonomia da Vontade está implícito no inciso II do artigo $5^{\circ}$ da $\mathrm{CF}$, o qual prevê que "ninguém 
será obrigado a fazer ou deixar de fazer alguma coisa senão em virtude de lei" (BRASIL, 1988). Ou seja, a Autonomia da Vontade pode ser limitada por dispositivo legal. Além da já mencionada situação de Emma, que demandou a tomada de decisão pelo senador Beffardi, e seu enquadramento ou não como homicídio, deve-se atentar que a assistência ao suicídio também é crime e, conforme previsto na cabeça do artigo 122 do Código Penal, não se fala em auxílio a suicídio do tipo privilegiado, com diminuição de pena (BRASIL, 1940).

Retorne-se ao caso das Diretivas Antecipadas de Vontade. Decerto que a Resolução $\mathrm{n}^{0}$ 1.995/2012 do CFM garante, conforme os parágrafos $3^{\circ}$ e $2^{\circ}$ do artigo $2^{\circ}$, que prevalecerão as Diretivas Antecipadas de Vontade sobre parecer não médico ou desejos de familiares, embora possa haver recusa do médico em seguir suas diretrizes quando houver discordância entre seu conteúdo e os preceitos delineados no Código de Ética Médica (CFM, 2012).

A Diretiva Antecipada de Vontade é, pelo menos no caso do Testamento Vital, negócio jurídico que funciona como meio de afirmação de direitos individuais, além de expressar a autonomia privada do paciente, a qual é possibilidade individual de se autodeterminar, ao expressar normas de caráter individual e com efeito vinculante em relação a médicos e parentes do doente. A autonomia privada complementa a Autonomia da Vontade e consagra a liberdade individual do enfermo terminal de realizar escolhas quanto aos tratamentos a que se submeterá ou não, em exercício pleno de seus direitos de personalidade (MARTINEZ; LIMA, 2016, p. 108).

Retirar a uma pessoa sua Autonomia é desfazer-se de sua consciência e de sua capacidade de fazer escolhas, ou seja, é negarlhe um traço que garante sua dignidade, sua humanidade. Assim, as Diretivas Antecipadas de Vontade garantem ao paciente em estado terminal a satisfação de um traço relevante de sua personalidade. 
3.2 A (IN)DIGNIDADE NA MORTE DE PACIENTES TERMINAIS: EUTANÁSIA, SUICÍDIO ASSISTIDO E ORTOTANÁSIA

Há de se diferenciarem, para melhor compreensão das questões ora debatidas, a Eutanásia, o Suicídio Assistido e a Ortotanásia. Quanto a Eutanásia, o termo é proveniente do grego e significa "boa morte". Caracteriza-se pela ação de "pôr fim à própria vida, em razão, normalmente, de doença grave e incurável, mas de maneira controlada e assistida por um médico especializado". Tratase, portanto, de tirar a vida do paciente por meio de intervenção médica, por administração de medicamento com fim de provocar sua morte. Em poucos países a prática é permitida (CALEGÁRIO, 2015, p. 27).

A Eutanásia consiste em "antecipar a morte de quem já está em estado irreversível", sendo a morte provocada por outrem, embora possa decorrer da vontade do paciente. Para alguns doutrinadores, há a impossibilidade de se requerer que "o Estado autorize a morte provocada para atenuar dor e sofrimento, ou mesmo por piedade", uma vez que "a vida se sobrepõe a qualquer outro direito" (CARVALHO, 2012, p. 20).

O impedimento de conceber-se a morte provocada com intuito de atenuar a dor e o sofrimento denota a tendência a considerar-se a vida como direito absoluto, supremo, do qual não se pode dispor, em qualquer circunstância que se apresente. Assim, à vida, a qual se encontra, em caso de estado terminal de doença, em fase final, que conduz à morte natural, se concederia posição hierarquicamente superior a qualquer outro bem jurídico, ainda que essa atitude possa retirar da própria vida o qualificativo da dignidade. Ademais, a vida 
como valor absoluto impede seu detentor de exercer plenamente sua Autonomia de Vontade, quando em situações de coma ou em estado terminal, que podem acarretar a indignidade de sua vida.

Quanto à Ortotanásia, a etimologia da palavra significa "morte correta", pois o prefixo "orto" significa correto, enquanto o sufixo "thanatos", morte (RECKZIEGEL; STEINMETZ, 2016, p. 97). A Ortotanásia é ato atípico no Código Penal Brasileiro e, portanto, não configura crime, por não ser causa da morte. Pela Ortotanásia, ao médico cabe tão-somente auxiliar para que o estado do paciente siga seu curso normal, omitindo-se em administrar medicamentos ou utilizar-se de equipamentos ou métodos prolongadores da vida do doente em estado terminal (CALEGÁRIO, 2015, p. 28).

No caso da Ortotanásia, o doente encontra-se em situação cujo resultado mais próximo e natural é a morte e não há como reverter-se o quadro pela cura. Assim, só se deixam de utilizar métodos que simplesmente prolongam a vida do paciente, como no caso de respiradores artificiais, quando ao paciente em estado terminal não seja mais possível respirar por conta própria, ou por meio do uso de medicamentos garantidores de sobrevida ao doente, embora the acometam ainda a dor e o sofrimento.

No caso apresentado no filme a embasar a discussão, o senador Beffardi, ao receber o pedido de sua esposa, encontra-se claramente em um dilema, qual seja: prolongar a vida de sua esposa, a qual está acometida por dor e sofrimento em decorrência de quadro de saúde irreversível, ou abreviar-lhe a vida, apressando seu falecimento, movido por amor e piedade. Ao escolher a segunda opção, pôde-se perceber sua dor e angústia, abraçado à mulher, desfalecida em seu corpo.

No caso supracitado, indaga-se qual o enquadramento do ato cometido, se Eutanásia ou Ortotanásia. A segunda alternativa se afigura mais adequada, já que não se utilizou de qualquer ato externo 
A (In)Dignidade nos Direitos à Vida e à Morte em Caso de...

para o resultado, mas desligou-se somente o aparelho que assegurava a sobrevivência da mulher. Portanto, tal ato, embora não precedido de Diretiva Antecipada de Vontade, não se enquadra como crime de homicídio, ao contrário de suposição já tratada, levando-se em conta o Código Penal nacional. Afinal, a vida de Emma caminhava para o desfecho natural, a morte, tendo o senador, somente, aliviado sua dor sem prolongar sua vida indevidamente, respeitando-lhe a Dignidade da Pessoa Humana, fundamento da ordem constitucional brasileira, e a Autonomia, traço relevante para a consecução da própria Dignidade.

O Suicídio Assistido, por outro lado, é o "ato em que um indivíduo, desejando morrer, provoca sua morte com o auxílio de outra pessoa”. Quando ocorre por assistência médica, o profissional da área auxilia com ministração de medicamentos ou fornecimento de informações e métodos necessários para que o paciente pratique o ato de matar-se, o que ocorre, de maneira geral, quando o enfermo se encontra acometido de doença incurável ou irreversível, sob o viés médico, que lhe cause muita dor e muito sofrimento (KRAVETZ; CASTRO, 2015, p. 353).

Enquanto a Eutanásia e o Suicídio Assistido são, claramente, pelo ordenamento jurídico nacional, considerados como homicídio (MARQUES; ALMEIDA, 2014, p. 12), a Ortotanásia não se pode considerar nem como homicídio nem como Suicídio Assistido e, por conseguinte, configura-se em caso atípico. As Diretivas Antecipadas de Vontade devem, pois, produzir efeitos quanto a Ortotanásia, não quanto às outras duas espécies.

Por outro lado, ocorre a situação de Eluana Englaro, jovem há dezessete anos em coma. Sabe-se que pessoas em coma podem, em algum momento, sair deste estado, motivo pelo qual a situação se mostra diversa daquela que acometeu Emma. Quanto ao fato em análise, portanto, restaria questionar se caberia ao Estado, aos familiares de Eluana ou a nenhuma das partes dispor acerca do 
desligamento dos aparelhos que lhe forneciam alimentação e lhe mantinham viva. Ademais, por via transversa, indaga-se sobre a existência de um dever de se respeitar a Dignidade dos familiares da paciente. Acresça-se, ainda, o questionamento se o desligamento dos aparelhos, nesse caso, configura-se como homicídio. É de se expor como deveria ser encarado o fato se Eluana pudesse, antes do estado de coma que lhe acometeu, ter manifestado sua vontade pela não manutenção de sua vida em caso de situações similares.

No Direito brasileiro, não se afigura defesa, a priori, da opção pelo não prolongamento da vida no caso de pacientes em coma, pois as Diretivas Antecipadas de Vontade, ainda controversas, não tratam deste tipo de situação. Em verdade, esses instrumentos abordam o caso de paciente acometido por doença terminal, o qual, quando em seu normal exercício de capacidade, pode, por si, ou, quando não esteja mais consciente, por representante que tenha nomeado anteriormente, decidir acerca de sua submissão ou não a tratamentos que tenham por escopo o prolongamento da vida, com adiamento de seu perecimento.

No caso de pessoa que não esteja acometida por doença terminal, mas em coma, o efetivo respeito do Princípio da Dignidade da Pessoa Humana, e de seu traço subjetivo da Autonomia da Vontade, deveriam conduzir à defesa de que, existindo Diretiva Antecipada de Vontade, seja Testamento Vital ou mediante mandatário nomeado pela pessoa para esse fim, se resguardasse o direito à descontinuidade da vida artificialmente. Essa possibilidade respeita os direitos fundamentais à vida digna e à morte digna, este corolário daquele, principalmente por não ser possível precisar, em muitas circunstâncias, o tempo que o paciente permanecerá em coma ou se seu quadro clínico mudará. As normas de diretos fundamentais, como já transcrito, são normas de otimização e, nesse viés, devem ser concretizadas na maior amplitude possível. 


\section{CONSIDERAÇÕES FINAIS}

Em face de todo o exposto na discussão, tomando-se por base o filme "Bella Addormentata", há o conflito entre a obrigatoriedade ou não de manutenção da vida humana, quando diante de pacientes em estado terminal ou de pessoas em coma. Nesse contexto, retratase a caracterização e definição do direito à vida e do direito à morte derivado do primeiro. Incidem, sobre o tema, a Autonomia da Vontade e o Princípio e fundamento da Dignidade da Pessoa Humana.

No Direito brasileiro, a Eutanásia e o Suicídio Assistido são verificados como atos delituosos, enquanto o caso da Ortotanásia em pacientes em estado terminal, especialmente pela previsão de Diretivas Antecipadas de Vontade, é tema polêmico, mas que não configura ilícito penal. Geram substrato à discussão, a manutenção da vida como pré-requisito para a personalidade, o direito à vida, o direito à morte, o fundamento da Dignidade da Pessoa Humana e a Autonomia.

Levando-se em consideração principalmente os direitos à vida digna e à morte digna, este último implícito, com fulcro no exposto no parágrafo $2^{\mathrm{o}}$ do artigo $5^{\mathrm{o}}$ da $\mathrm{CF}$, é razoável permitir-se aos pacientes em estado terminal que, por meio de Diretivas Antecipadas de Vontade ou pela manifestação inequívoca de sua vontade por qualquer forma, possam optar pela morte. Esta resta instrumentalizada, legalmente, pela Ortotanásia, ou seja, pela simples ausência de prolongamento artificial da vida do paciente.

Igualmente, tal direito deve ser assegurado aos pacientes em estado de coma, caso estes se manifestem de alguma forma antes de 
se encontrarem acometidos pelo estado em que não podem expor sua vontade, ou mediante escolha realizada pelo mandatário previamente nomeado para esse fim. Assim, concretizam-se tanto o direito à morte digna quanto o direito à vida digna, já que não se pode falar em um direito à vida como sendo simplesmente o direito a estar com vida, pelo fato de que a Dignidade da Pessoa Humana é fundamento do Estado Democrático de Direito e deve balizar a interpretação dos direitos fundamentais. Retirar-se a Autonomia de Vontade da pessoa nestas circunstâncias é negar-lhe traço humano fundamental, característico da própria Dignidade da Pessoa Humana.

No mesmo sentido, é de se observar que os direitos fundamentais, como os direitos à vida e à morte dignas, requerem aplicação otimizada no caso concreto. Por conseguinte, ainda que não haja, explicitamente, nenhum dispositivo que salvaguarde o direito de o paciente em coma, que não esteja em estado terminal, optar, previamente, pela morte digna, especialmente a partir da Ortotanásia, a otimização do exercício do direito à morte digna e do direito à vida digna demanda que se garantam os efeitos da manifestação da vontade do paciente.

Data de Submissão: 14/04/2018

Data de Aprovação: 20/10/2018

Processo de Avaliação: double blind peer review

Editor Geral: Jailton Macena de Araújo

Editor de Área: Fernando Joaquim Ferreira Maia

Assistente Editorial: Caroline Helena Limeira Pimentel Perrusi 
A (In)Dignidade nos Direitos à Vida e à Morte em Caso de...

\section{REFERÊNCIAS}

BRASIL. Constituição (1988). Constituição da República Federativa do Brasil, Brasília, DF, Senado, 1988.

BRASIL. Decreto-Lei ${ }^{0}$ 2.848/40. Código Penal, Brasília, DF, Senado, 1940.

BRASIL. Lei ${ }^{0}$ 10.406/2002. Código Civil, Brasília, DF, Senado, 2002.

CALEGÁRIO, Jéssica Maria Fonseca. Eutanásia: uma ótica jurídica, psíquica, e a construção do conceito individual de dignidade. Panóptica, Vitória, v. 10, n. 2, p. 26-34, 2015. Disponível em: $<$ http://www.panoptica.org/seer/index.php/op/article/view/35o/pd f_1>. Acesso em: 12 out. 2016.

CARVALHO, Adriana Pereira Dantas. Direito de morrer de forma digna: autonomia da vontade. Revista Jurídica Orbis, Campina Grande, v. 3, n. 2, p. 15-29, 2012. Disponível em: $<$ http://cesrei.com.br/ojs/index.php/orbis/article/view/104>. Acesso em: 13 out. 2016.

CHIMENZ, Marco; LAURENTIIS, Matteo de (prod.); BELLOCCHIO, Marco (dir.). Bella Addormentata. [Filme-Vídeo]. Produção de Marco Chimenz e Matteo de Laurentis, direção de Marco Bellocchio. França; Itália, California Films, 2013. Compact Disc (CD), 110 min. Drama.

CONSELHO FEDERAL DE MEDICINA (CFM). Resolução no 1.995/2012, Conselho Federal de Medicina, 2012. Disponível em: < http://www.cremesp.org.br/?siteAcao=PesquisaLegislacao\&dif=s\&fi cha $=1 \&$ id $=10938 \&$ tipo $=$ RESOLU $\% \mathrm{C}_{7} \% \mathrm{C}_{3}$ O\&orgao $=$ Conselho\%20Fe deral\%20de\%20Medicina\&numero=1995\&situacao=VIGENTE\&data =09-08-2012>. Acesso em: 06 dez. 2016.

COSTA, Cássio de Sales; DUARTE, Hugo Garcez. Direito à vida e distanásia: por um apontamento democrático. Bonijuris, Curitiba, v. 28, n. 6, p. 6-10, jun. 2016. Disponível em: $<$ https://app.vlex.com/\#WW/search/content type:4/Direito+\% $3 \%$

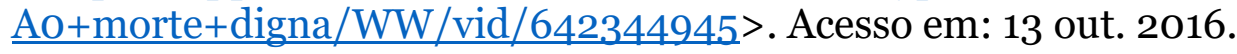

DIAS, Patrícia Cardoso. Diretivas Antecipadas de Vontade: novos desafios para a compreensão do sistema jurídico pela consagração do instituto da representação voluntária em matéria de direitos de personalidade. Opinião Jurídica, Fortaleza, a. 14, n. 19, p. 228252, jul./dez. 2016. Disponível em: 
<http://periodicos.unichristus.edu.br/index.php/opiniaojuridica/art icle/view/930/398>. Acesso em: 04 out. 2018.

FREITAS, Riva Sobrado de; ZILIO, Daniela. O direito à morte digna sob a perspectiva do direito à autonomia do paciente terminal. Revista de Biodireito e Direitos do Animais, Brasília, v. 2, n. 1, p. 196-212, jan./jun. 2016. Disponível em: <http://www.indexlaw.org/index.php/revistarbda/article/view/281/ pdf_1>. Acesso em: 02 out. 2018.

GIL, Antonio Carlos. Como elaborar projetos de pesquisa. 4. ed. São Paulo: Atlas, 2002.

KRAVETZ, Rafaella Zanatta Caon; CASTRO, Matheus Felipe de. O suicídio assistido na esfera dos direitos fundamentais: análise da autonomia da vontade na sociedade disciplinar. Revista Jurídica do Centro Universitário Curitiba, Curitiba, v. 2, n. 39, p. 346372, 2015. Disponível em: <http://revista.unicuritiba.edu.br/index.php/RevJur/article/view/1 537/1052>. Acesso em: o5 dez. 2016.

LOPES, Ana Maria D'Ávila. Os Direitos Fundamentais como limites ao poder de legislar. Porto Alegre: Sergio Antonio Fabris Editor, 2001.

MARQUES, Anna Valéria de Miranda Araújo Cabral; ALMEIDA, Ana Cláudia Albuquerque de. Diretivas antecipadas da vontade através do testamento vital: oportunidade de humanização da morte. Direito e Desenvolvimento, João Pessoa, v. 5, n. 10, p. 9-27, jul./dez. 2014. Disponível em: <http://www.revistartj.org.br/ojs/index.php/rtj/article/view/240>. Acesso em: 01 dez. 2016.

MARTINEZ, Sergio; LIMA, Adaiana. O testamento vital e a relação médico-paciente na perspectiva da autonomia privada e da dignidade da pessoa humana. Revista de Bioética y Derecho - Perspectivas bioéticas, Barcelona, n. 37, p. 103-120, maio 2016. Disponível em: < http://revistes.ub.edu/index.php/RBD/article/view/16153>. Acesso em: 05 dez. 2016.

PORTUGAL. Lei $n^{0}$ 25/2012. Regula as diretrizes antecipadas de vontade, designadamente sob a forma de testamento vital, e a nomeação de procurador de cuidados de saúde e cria o Registro Nacional do Testamento Vital (RENTEV), Lisboa, Assembleia da República, 2012. Disponível em: < https://dre.pt/application/conteudo/179517>. Acesso em: o5 out. 2018.

RECKZIEGEL, Janaína; STEINMETZ, Wilson. Cuidados paliativos e o direito à morte digna. Direito Público, Porto Alegre, v. 13, n. 72, p. 91-114, nov./dez.2016. Disponível em: 
A (In)Dignidade nos Direitos à Vida e à Morte em Caso de...

$<$ https://www.portaldeperiodicos.idp.edu.br/direitopublico/article/v iew/2574/pdf>. Acesso em: 02 out. 2018.

SARLET, Ingo Wolfgang. Dignidade da pessoa humana e direitos fundamentais na Constituição Federal de 1988. 7. ed. Porto Alegre: Livraria do Advogado, 2009.

XEREZ, Rafael Marcílio. Concretização dos direitos fundamentais: teoria, método, fato e arte. Rio de Janeiro: Lumen Juris, 2014. 


\title{
The (In)Dignity on Rights to Life and to Death on Cases of Terminal Illness or Coma Patients Based on the Film "bella addormentata"
}

\author{
Rafael Marcílio Xerez \\ Humberto Cardoso Pinto
}

\begin{abstract}
The right to dignified death generates opposite opinions on juridical environment, specially over the possibility of decision for the discontinuity of life by terminal ill people or patients in coma. The discussion happens over Human Dignity and Autonomy of Will because on cases of incurable and terminal illness the conservation of life by medicaments and equipment usually generates pain and suffering to patients. The questions involving methods as Euthanasia, Orthanasia and Assisted Suicide as well as Anticipated Will Directive as possibilities to patients divide opinions. The film "Bella Addormentata" treats theses questions, specially on case of Eluana Englaro, in coma for seventeen years, which brought questions about the compulsory or not of the conservation of life of patients in coma. The research is bibliographical and documental. Its objective is to analyze if it might be assured to a terminal patient or the one in coma the right to choose death over the enlargement of their life by artificial means. As a fundamental right, the right to dignified death should be assured to patients in coma or the terminal ones if they can manifest in advance their will of non-submission to treatments that extend life.
\end{abstract}

Keywords: Right to dignified death. Euthanasia. Assisted Suicide. Orthanasia. Anticipated Will Directive. 